\title{
Assessing the Energy Efficiency and Daylight Performance of Windows in Buildings in Nur-Sultan, Kazakhstan
}

\author{
Abid Nadeem* ${ }^{*}$, Alexey Sharipov, Yerzhan Abzhanov \\ Department of Civil and Environmental Engineering, Nazarbayev University, Nur-Sultan, Kazakhstan \\ E-mail: abid.nadeem@nu.edu.kz
}

Received: 24 June 2021; Revised: 22 October 2021; Accepted: 26 October 2021

\begin{abstract}
The importance of research on sustainable and energy-efficient building design is increasing, considering that humanity may face a shortage of natural resources as a result of irrational energy use. This article focuses on optimising the window characteristics of the buildings to be constructed in Nur-Sultan, Kazakhstan, in order to improve their energy efficiency and daylight performance. Specifically, simulations were performed with the DesignBuilder software to study the effects of the window-to-wall ratio (WWR), glazing type, shading, and building orientation on the energy performance of the building and the comfort level of the occupants. As a result, triple-pane windows with 10 to $15 \%$ WWR oriented mainly to the south were found to have better performance compared to other configurations. However, a life-cycle analysis can be performed to verify its benefits in terms of cost and environmental burden. On the other hand, limitations of the glazed area on each facade may affect the comfort level of the occupants in terms of temperature increases, lack of daylight, and poor ventilation. Thus, a discussion of the simulation results is provided, along with issues that might arise. Suggestions for future studies were also included.
\end{abstract}

Keywords: energy consumption, energy efficiency, window characteristics, daylight, glazing, window-to-wall ratio

\section{Introduction}

Energy is always considered one of the critical factors, a vehicle for the flourishing of civilisation. The shortage and waste of this valuable resource will lead to an inevitable crisis of humanity in terms of economic, social, and environmental aspects [1]. However, the current unsustainable use of natural resources and massive energy consumption, especially in developed countries, may bring that day closer than expected. Thus, studies geared toward energy efficiency have become one of the most critical directions within the research community.

The development of energy efficiency performance in the design of buildings is considered a promising approach to resolve this problem, as the building sector is responsible for almost $40 \%$ of the total energy produced, increasing by $1.8 \%$ each year, thus being one of the largest consumers in the energy market [2]. It is essential to focus on long-term analysis of the energy efficiency performance of buildings, as the construction phase is responsible for only 10 to $20 \%$ of the total energy in the building life cycle. The rest of the energy is consumed for subsequent operation and maintenance of buildings [3].

Due to its cold climate, a significant amount of energy is consumed for space heating in Kazakhstan. For example,

Copyright (C2021 Abid Nadeem, et al

DOI: https://doi.org/10.37256/gbce.222021969

This is an open-access article distributed under a CC BY license

(Creative Commons Attribution 4.0 International License)

https://creativecommons.org/licenses/by/4.0/ 
in 2002, the demand for building heating energy accounted for 160 million Gcal, approximately $60 \%$ of the total energy consumption, including heating and electricity. Urban areas consume more than $60 \%$ of the total heating energy, $80 \%$ of which is due to residential buildings. After energy and manufacturing, housing is the third-largest energy consumer and a significant source of greenhouse gas emissions. In general, energy production in Kazakhstan produces $80 \%$ of all greenhouse gas emissions, and $90 \%$ of it is the repercussion of heat and electricity production. Additionally, residential buildings make up $13.5 \%$ of the national electricity demand and $24 \%$ of the national heating demand [4].

Kazakhstan's energy audit in 2010 revealed that the heating energy consumption of residential buildings is considerably higher than that of western countries. The average specific consumption of heat energy was $273 \mathrm{kWh} / \mathrm{m}^{2}$. In comparison, the average European value was around 100 to $120 \mathrm{kWh} / \mathrm{m}^{2}$, and for further comparison, particularly in Finland, it was $140 \mathrm{kWh} / \mathrm{m}^{2}$ [5]. There are more than 5000 cooling and heating degree days in Kazakhstan per year, including approximately 4500 heating degree days. It is the fourth-highest value among the European Bank for Reconstruction and Development (EBRD) countries after Mongolia, the Russian Federation, and Finland. Therefore, the housing sector significantly impacts energy consumption, mainly heating energy demand [4].

The energy efficiency of residential buildings is an issue of great importance. It can be stated that passive house design has become one of the most significant achievements in this direction. The first passive house with enormous efficiency was built in Darmstadt, Germany, by Wolfgang Feist and Bo Adamson in 1990. Subsequently, they established the Passive House Institute in 1996 [6]. The technology of the passive house is focused on maximising the efficient use of internal heat resources, namely the heat generated by the residents of the house, household appliances, solar radiation, exhaust air, and others, which allows maximum conservation and accumulation of heat [7]. Such advanced technologies have also been implemented later in Kazakhstan. However, only 39 buildings were sustainable enough in energy efficiency to be certified by Leadership in Energy and Environmental Design (LEED) and Building Research Establishment Environmental Assessment Method (BREEAM) standards [8]. This trend was also highlighted by Akhanova et al. [9], which could be attributed to the extreme climatic conditions in Kazakhstan.

Regardless of the standard or design method used in constructing the building, the crucial factors to consider are the environmental and weather conditions where the building will be located. Therefore, the macro and micro needs of passive design must be considered [6].

Case studies demonstrate that energy-efficient building designs can show different behaviours in different climatic conditions. For example, the energy savings potential of a particular design is equal to $12.61 \%$ in Brisbane, Australia, with warm, humid summers and mild winters, and may increase to $39.46 \%$ in Alice Springs, Australia, with hot, dry summers and warm winters [10]. On the other hand, increasing energy efficiency, such as increasing the window-towall ratio (WWR) beyond 34\%, will have no effect on tropical climates [11]. Furthermore, research shows that higher altitudes with higher solar irradiance and wind conditions may positively impact the energy performance of the building in terms of cooling. For instance, 2.7\% savings were achieved in Phoenix, USA, at an elevation of $339 \mathrm{~m}$ above sea level, compared to $56.7 \%$ savings in Calama, Chile, at an elevation of $2312 \mathrm{~m} \mathrm{[12].}$

The technology of a passive house provides effective thermal insulation of all enclosed surfaces: walls, windows, roofs, and floors. Several layers of thermal insulation are formed in a passive place, usually grouped into internal and external, which simultaneously keeps the heat inside the house and prevents the penetration of cold air from outside [6]. Thus, the most effective way to increase the energy efficiency of buildings is by properly insulating the walls. For that purpose, passive house design requires the heat transfer resistance or R-value of the envelope to be higher; for example, such an insulator as extruded polystyrene has a higher R-value and contributes to up to $31.4 \%$ energy savings [13].

Based on an energy audit performed in Kazakhstan from 2011 to 2015, several options to improve the energy efficiency of buildings were examined. It is noted that the energy performance of residential buildings can be substantially improved, primarily due to current inefficient technologies and building envelopes. The audit results revealed that the insulation quality was worse compared to the European countries. For instance, in regions with 6000 heating degree days, the average U-value in Europe is around $0.2 \mathrm{~W} / \mathrm{m}^{2} \mathrm{~K}$, while in Kazakhstan, it is approximately $1.05 \mathrm{~W} / \mathrm{m}^{2} \mathrm{~K}$. Among some measures proposed to improve energy performance, the replacement of existing windows was considered ineffective. However, the retrofitting of windows of communal entrances is indicated as one of the reasonable solutions, with a relatively low payback period and investment cost [14].

Around $70 \%$ of buildings are estimated to have thermal characteristics that do not meet current requirements in Kazakhstan. As a consequence, up to $30 \%$ of the delivered heating energy dissipates through the building envelope. 
In 2012, Nur-Sultan spent 2,413,000 GCal on space heating, accounting for $9.86 \%$ of total heating energy consumed in Kazakhstan [5]. The population of Nur-Sultan in 2012 was 778,145 [15]. It will substantially increase to 1,207,300 by July 1st, 2021 [16]. Hence, minimising heat loss and enhancing the energy performance of buildings in Nur-Sultan is highly important within the scope of this paper. Although the building envelope is believed to be the most affecting factor, it is also essential to evaluate the influence of window characteristics and WWR; moreover, its vital role tends to be unreasonably underestimated in some cases.

The present study investigates the influence of ten different windows representing single, double, and triple glazing, their orientation, and the variation of WWR within the range of 0 to $60 \%$ on the energy performance of the reference building located in Nur-Sultan, Kazakhstan. The effects of the WWR were also discussed concerning the thermal and visual comfort of the occupants. Research is based on numerical simulations using the EnergyPlus tool integrated with DesignBuilder software. The local Nur-Sultan climate (extreme continental climate with hot summers and severely cold winters) was used.

This paper comprises five sections. The first is an introduction to the importance of energy performance issues within the Kazakhstan building sector. Then, an existing literature review related to the subject matter is presented. The third part represents the methodology used, and the fourth elaborates on the obtained results. Finally, a summary of the paper and suggestions for further research are provided.

\section{Literature review}

Many studies have been conducted to provide optimal window properties to enhance building energy performance. However, the research results vary between scholars, and no single and explicit solution is provided. Windows are an essential part of the envelope in passive house design due to their lower R-value than external walls. Window glasses allow radiation to pass in the infrared range, responsible for two-thirds of heat losses [17]. Thus, sufficient layers of proper glazing are required to minimise heat losses.

Two-thirds of heat loss through windows is radiation (in the infrared range from the house to the outside). The southern direction of the passive house's main façade, within a 30\% deviation in the western or eastern direction, provides the most optimal active and passive use of solar energy. During installation, special attention must be paid to the proper installation of window structures: to ensure careful sealing of the heat-insulating layer while controlling the tight connection at the joints. Otherwise, it may damage the integrity of the building envelope. This approach to optimising window characteristics considering external conditions contributes to up to $24 \%$ of total energy savings [18].

Alibaba [19] showed that the WWR might positively influence the energy savings potential by up to $60 \%$. On the other hand, other research showed that the most optimal WWR is in the range of 10 to $22.5 \%$ for cold-weather zones [20].

Yang et al. [21] evaluated the effect of WWR on the energy performance of buildings in China's hot summer and cold winter regions. They considered different modes of operation of air-conditioning (A/C) systems. Although the selected regions have cold winters, they were cooling-dominated. The simulation results showed that increasing the WWR increases annual energy consumption, and the patterns are similar for varying $\mathrm{A} / \mathrm{C}$ modes. Compared to the north and south facades, the expansion of the east and west windows significantly affected the energy demand of the building. In addition, in contrast to hollow glass, the low emissivity (Low-E) window demonstrated better performance by considerably flattening the energy consumption plots.

Liu et al. [22] investigated the optimal WWR of residential buildings in the same climates of China. According to the results of the questionnaire investigation, existing dwellings with a higher WWR have a higher energy demand and correlate with the simulation results of Yang et al. [21]. However, contrary to the findings of Yang et al. [21], the simulation results of Liu et al. [22] revealed that the heating demand is higher than the cooling demand in China's hot summer and cold winter climates. A WWR of 40 to $50 \%$ was proposed as the optimal solution for energy efficiency for the three types of residential buildings, such as a detached house, multi-story building, and high-rise building. The importance of decreasing the north-side WWR is also mentioned since, in regions with cold and long winters, a large fenestration area contributes to significant heat losses during the heating period.

Strengthening the thermal insulation on the outside requires increasing the thermal insulation of the walls and reducing the thermal bridges, which are unavoidable in any building. Different types of insulation are provided not only 
for walls but also for coatings, ceilings, foundations, and window systems. Thus, the area of thermal bridges increases with the size of the windows, compromising the envelope's airtightness. On the other hand, minimising air infiltration through a properly airtight envelope allows for up to 25 to $50 \%$ of heat losses and increases energy efficiency [7].

Ihm et al. [23] examined the effect of window type on the energy efficiency of domestic buildings in South Korean climates. Six types of windows and two different window distributions on the building façade were compared and investigated. In the first case, WWR was identical on each wall, and in the second case, the southern side had most of the building's glazed area. However, the window distribution had no significant effect on the energy performance. Although the triple-glazed Low-E window demonstrated good performance, its use was unfavourable for life cycle cost analysis. Subsequently, double-glazed clear Low-E windows filled with argon were recommended for residential buildings in South Korea. The study found that for a low WWR building in South Korea's cold climate, among windows with similar thermal conductivity (U-values) and different solar heat gain coefficient (SHGC) values, the one with higher solar conductivity leads to savings on annual energy consumption. Therefore, it is emphasised that the country's building codes should consider adopting SHGC requirements.

It is also essential to choose the appropriate architectural form of the structure, which must undoubtedly fit the climate and landscape of the construction area. Properly designed building geometry is one of the best approaches to passive energy savings. Thus, a square shape is preferred for lower WWR. Additionally, during construction, reconstruction, or expansion of the building, whenever possible, all kinds of niches, ledges, and ledges on the walls should be avoided. It makes sense to build unheated annexes on the north side of the house. Due to the lower surface area coefficient, ordinary houses and apartment buildings have advantages over detached single-family dwellings. This passive design recommendation helps to reduce energy losses by $26 \%$ [24].

Susorova et al. [25] investigated the effect of WWR, orientation, and room-depth ratio on the energy efficiency of office buildings in six different climates of the United States. The WWRs changed significantly for rooms with low width-depth ratios in hot regions and higher width-depth ratios in cold regions. Consequently, heat loss through the building envelope is a significant concern; low WWR is recommended for shallow spaces, and higher WWR for deep spaces. It was suggested that in cold climates, building energy performance could benefit from reducing the WWR of north facades and increasing it on the southern side since the more significant heat gain through south-oriented windows may decrease the heating load. The south-oriented rooms showed the most incredible energy performance among all the orientations and climate zones examined. However, this study concluded that optimising the geometry aspects of building fenestration has a marginal influence on the energy efficiency of buildings located in cold climates.

$\mathrm{Su}$ and Zhang [26] conducted life cycle assessment-based research for an office building. They examined the environmental performance of various window types with WWRs ranging from 10 to $70 \%$. Fuel consumption, the effect on global warming, and atmospheric emissions were considered to assess the environmental impact of the building envelope. It was discovered that increasing WWR improves life cycle energy efficiency and reduces environmental pollution. This research showed that single-glazed windows have a higher environmental impact compared to hollow glass and Low-E hollow glass windows. It should be noted that varying the WWR of hollow glass and Low-E glass windows marginally affects environmental performance, providing designers and architects more flexibility in building aesthetics. Regarding the life cycle of the building, they determined that the environmental impact of the appropriate window glazing type is more significant than the choice of an accurate WWR. Furthermore, within the same context, the research concluded that utilising windows with lower thermal conductivity is more efficient than finding a precise WWR.

Kaasalainen et al. [27] stated that many previous studies mainly focused on optimising WWR and glazing types. Therefore, several characteristics of the window design, such as its shape (from narrow to wide), the horizontal location on the facade of the building, the length of the external shading element, and the shape of the apartment, were considered in their research in three different climate regions in Finland. However, while the same area was kept, varying the horizontal location and shape of the window had no significant effect on the apartments' energy performance. The results also showed that larger window areas decrease lighting energy and increase heating and cooling energy, whilst still increasing total energy consumption. The authors suggest that it is not always necessary to reduce the WWR to achieve energy efficiency in cold climates, and that medium to large window areas with high solar transmittance and external shading minimise energy consumption.

The importance of the required cooling energy for well-insulated buildings with large WWR in the cold northern 
climates, excluding north-oriented windows, was also mentioned. The same study revealed that external shading improved energy performance in $62.4 \%$ of all simulated cases. The reduction in the need for cooling was more significant than the increase in the energy need for heating and lighting. It is worth noting that low g-values (the effect of glazing and is referred to as solar factor) may compensate for a lack of external shading, and vice versa. This research was consistent with other studies showing that windows with lower thermal transmittance reduced energy consumption. It has a significant impact in regions dominated by heating. The comparison of windows with equal U-values and different g-values demonstrated that higher solar transmittance improves the energy efficiency of buildings in a cold climate, which corresponds to the findings of Ihm et al. [23].

It should be pointed out that Kaasalainen et al. [27] emphasised the importance of investigating several window features in combination with each other. According to the research results, design options that benefit heating energy consumption may also increase cooling energy needs, and vice versa. In addition, they claim that reducing heating loads and increasing solar heat gains should acquire more attention, as in cold climates, most of the total energy consumption is due to high heating needs.

In ordinary houses, windows serve as equipment for natural ventilation and sunlight penetration.Thus, the limitation of WWR may negatively affect such properties of the building. However, Sadineni et al. [17] argued that advanced soundproof sealed windows can provide proper ventilation, increasing energy savings by $30 \%$. Tubular skylights can accumulate and distribute sunlight, thus increasing daylight and saving $20 \%$ on general lighting [28]. In the study by Harmati and Magyar [29], the optimal WWR and window geometry were investigated in relation to the quality of indoor daylight in an office building in Serbia. Three different window shapes were examined: square, rectangular horizontal, and rectangular vertical. The results demonstrated that vertical windows resulted in a more favourable daylight distribution.

The appropriate WWR for the east and west facades was 30\%, $20 \%$ for the north side, and $25 \%$ for the southoriented offices. Other factors, aside from window size and shape, were not considered to improve daylight performance. At the same time, only the type of glazing was analysed to address the energy efficiency of the building [29].

Ochoa et al. [30] also stated that research outputs aimed at improving one objective could impair another. As a result, multiple simulations were performed in their study to find the optimal WWR to satisfy both energy efficiency and visual comfort requirements for reference offices with a window located only on one side and a WWR ranging from 0 to $100 \%$. The climate of the Netherlands was considered, and the term "critical region" was introduced as the threshold WWR value where daylight's effect on lighting energy saving ceases It had a value of $70 \%$ for the north orientation and $60 \%$ for the east, west, and south orientations. Hence, there is more flexibility provided for designers to address efficient energy use and visual comfort. However, it is suggested to acknowledge the importance of using shading devices, advanced glazing types, and blinds.

In general, it is essential to perform investigations based on local climate data and to consider multiple aspects of window design and building features. According to Kaasalainen et al. [27] and evidence from studies by Liu et al. [22] and Yang et al. [21], the energy performance of buildings located within the same climate zone can differ considerably. Thus, this research aims to investigate the optimal glazing type, WWR, and orientation for the buildings and climate of Nur-Sultan. It should be emphasised that there is a lack of studies that analyse the energy efficiency and daylight performance of buildings in Kazakhstan. Hence, this paper may show the demand for future studies in this field.

\section{Methodology}

A numerical simulation was performed using DesignBuilder software integrated with the EnergyPlus tool to achieve the research goal proposed in the previous section. EnergyPlus is a vital energy simulation tool that allows for the analysis of the energy performance of the entire building. Integrated simulation of loads, systems, and plants is the main advantage of this software [31]. As later stated by Crawley et al. [32], it is an indispensable feature for designing systems and plants and assessing occupants' thermal comfort. EnergyPlus allows users to configure heating, ventilation, and air conditioning (HVAC) systems, define simulation time steps, and have easy-to-use input and output data formats, promoting the visualisation of results [12]. DesignBuilder is used as a user interface to run EnergyPlus and enables the modelling of a detailed building design and executing a complete energy performance analysis [33]. According to 
González and Yousif [34], DesignBuilder facilitates numerical analysis of particular building energy efficiency measures and allows for a comprehensive evaluation of results. The following sections briefly explain the simulation process performed to achieve the objectives of the research paper.

\subsection{Input data}

\subsubsection{Location}

First, the necessary information about the location and weather conditions was entered into the software. The input data for the location section is summarised below:

- Nur-Sultan, Kazakhstan

- Elevation above sea level: $347 \mathrm{~m}$

- Latitude: $51.13^{\circ}$

- Longitude: $71.37^{\circ}$

- Koppen classification: Dfb (humid continental climate of the summer)

- Average annual temperature: $2.2^{\circ} \mathrm{C}$

- Warmest average temperature: $20.7^{\circ} \mathrm{C}$ (July)

- Coldest average temperature: $-21.4^{\circ} \mathrm{C}$ (February)

- Annual precipitation: $308 \mathrm{~mm}$

\subsubsection{Building characteristics}

A two-story building with simple planning and a total built-up area of $\sim 240 \mathrm{~m}^{2}$ was constructed in the software (Figure 1). It was also assumed that the natural gas system was used for heating and a central air conditioning system for cooling.

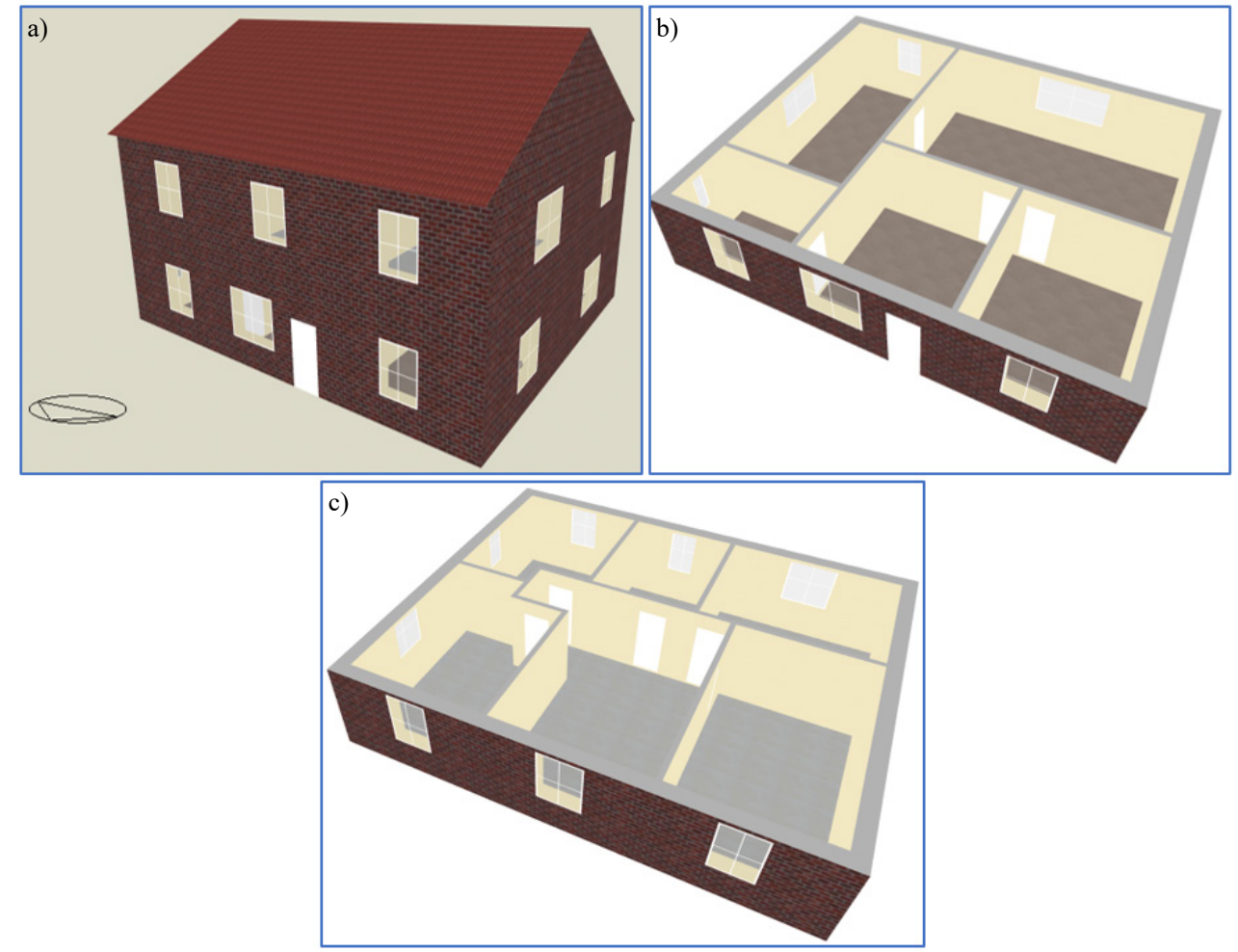

Figure 1. (a) 3D model, (b) 1st-floor plan, and (c) 2nd-floor plan of the reference building 
The characteristics of the building, namely geometry, envelope, materials (Table 1), usage of the building (occupancy, lighting, equipment, appliances, HVAC, etc.), and other properties were entered, taking into account the standard practises of occupancy.

The occupancy density was set as 0.0155 people $/ \mathrm{m}^{2}$. Dwell domestic circulation was selected for the residential type of building. The schedule of activities is as shown in Table 2.

Table 1. Characteristics of the building envelope

\begin{tabular}{ll}
\hline & \multicolumn{1}{c}{ Characteristics of the building envelope } \\
\hline Roof & $25 \mathrm{~mm}$ Clay Tile Roofing, 242.3 mm MW Stone Wool, $5 \mathrm{~mm}$ Roofing Felt \\
External Walls & $\begin{array}{l}100 \mathrm{~mm} \text { Brickwork Outside, 171.3 mm XPS Extruded Polystyrene - CO2 Removal, } 100 \mathrm{~mm} \text { Concrete Block } \\
\text { (medium), } 13 \mathrm{~mm} \text { Gypsum Plastering }\end{array}$ \\
Partitions & $13 \mathrm{~mm}$ Gypsum Plastering, $115 \mathrm{~mm}$ Brickwork Inner, $13 \mathrm{~mm}$ Gypsum Plastering \\
Internal Floor & $100 \mathrm{~mm}$ Cast Concrete \\
Ground Floor & $132.7 \mathrm{~mm}$ Urea-formaldehyde foam, $100 \mathrm{~mm}$ Cast Concrete, $70 \mathrm{~mm}$ Floor Screed, $30 \mathrm{~mm}$ Timber Flooring \\
\hline
\end{tabular}

Table 2. Activity schedule

\begin{tabular}{ll}
\hline Type & Schedule \\
\hline Occupancy & $00: 00-07: 00-0 \% ; 07: 00-10: 00-100 \% ; 10: 00-19: 00-0 \% ;$ \\
& $19: 00-23: 00-20 \% ; 23: 00-24: 00-0 \%$ \\
Equipment & $00: 00-07: 00-6 \% ; 07: 00-08: 00-53 \% ; 08: 00-09: 00-100 \% ;$ \\
& $10: 00-17: 00-6 \% ; 17: 00-18: 00-30 \% ; 18: 00-19: 00-53 \% ;$ \\
& $19: 00-20: 00-77 \% ; 20: 00-22: 00-100 \% ; 22: 00-23: 00-77 \% ; 23: 00-24: 00-30 \%$ \\
Lighting & $00: 00-07: 00-0 \% ; 07: 00-10: 00-100 \% ; 10: 00-19: 00-0 \% ;$ \\
& $19: 00-23: 00-100 \% ; 23: 00-24: 00-0 \%$ \\
Heating & $00: 00-05: 00-50 \% ; 05: 00-10: 00-100 \% ; 10: 00-17: 00-50 \% ;$ \\
& $17: 00-23: 00-100 \% ; 23: 00-24: 00-50 \%$ \\
Cooling & $00: 00-05: 00-0 \% ; 05: 00-10: 00-100 \% ; 10: 00-17: 00-0 \% ;$ \\
& $17: 00-23: 00-100 \% ; 23: 00-24: 00-0 \%$ \\
\hline
\end{tabular}

Regarding the activities mentioned above, $11.7 \mathrm{~W} / \mathrm{m}^{2}$ equipment and $5 \mathrm{~W} / \mathrm{m}^{2}$ lighting loads were chosen. The lighting settings were adjusted to achieve 150 lux illuminance in the rooms. Finally, the temperature settings for the heating and cooling control were set, as shown in Table 3.

Table 3. Setpoints of heating and cooling temperatures

\begin{tabular}{lll}
\hline \multicolumn{3}{c}{ Setpoints of heating and cooling temperatures } \\
\hline Heating temperatures $\left({ }^{\circ} \mathrm{C}\right)$ & Heating setpoint & 16 \\
& Heating set back & 14 \\
Cooling temperatures $\left({ }^{\circ} \mathrm{C}\right)$ & Cooling setpoint & 24 \\
& Cooling set back & 26 \\
\hline
\end{tabular}

\subsection{Simulation process}

After defining all the necessary parameters, the simulation started. The simulation procedure was repeated many times with different parameters to investigate. Specifically, the output for different window characteristics settings such as orientation, WWR, glazing type, and shading was compared. All simulations were grouped into three types according to the properties to be tested: WWR, orientation, and window glazing. 


\subsubsection{Orientation}

As discussed in the literature review, the orientation of buildings has a significant effect on the performance of the windows. The building has a different area of windows on each side. Thus, it is also essential to determine which side of the building should have the largest windows.

\subsubsection{Window-to-wall ratio (WWR)}

The WWR is one of the most important factors influencing both occupants' energy savings and comfort. Therefore, numerical simulations were performed with different WWR ranging from 0 to $60 \%$ with a $5 \%$ increment. Additional simulations with smaller steps may be required for optimisation.

\subsubsection{Window glazing}

In addition to the WWR testing, the effect of different window glazings, specifically the number of panes, thickness, tinting, insulation, and presence of other films, was tested.

Table 4. Types of window glazing

\begin{tabular}{|c|c|c|c|c|}
\hline \multicolumn{2}{|c|}{ Window glazing type } & \multirow{2}{*}{$\begin{array}{c}\text { Designated by } \\
\mathrm{SgCl} 3 \mathrm{~mm}\end{array}$} & \multirow{2}{*}{$\frac{\mathrm{U} \text {-value }\left(\mathrm{W} / \mathrm{m}^{2} \mathrm{k}\right)}{6.257}$} & \multirow{2}{*}{$\begin{array}{c}\begin{array}{c}\text { Solar heat gain coefficient } \\
\text { (SHGC) }\end{array} \\
0.861\end{array}$} \\
\hline Single-pane window & Clear $3 \mathrm{~mm}$ & & & \\
\hline & Clear $6 \mathrm{~mm}$ & $\mathrm{Sg} \mathrm{Cl} 6 \mathrm{~mm}$ & 6.121 & 0.819 \\
\hline & Blue $6 \mathrm{~mm}$ & $\mathrm{Sg} \mathrm{Bl} 6 \mathrm{~mm}$ & 6.121 & 0.620 \\
\hline & Bronze $6 \mathrm{~mm}$ & $\mathrm{Sg} \mathrm{Br} 6 \mathrm{~mm}$ & 6.121 & 0.620 \\
\hline \multirow[t]{3}{*}{ Double-pane window } & Clear $6 \mathrm{~mm}-13 \mathrm{~mm}$ Air & $\mathrm{Db} \mathrm{Cl} 6 \mathrm{~mm}$ & 2.708 & 0.703 \\
\hline & Blue $6 \mathrm{~mm}-13 \mathrm{~mm}$ Air & $\mathrm{Db} \mathrm{Bl} 6 \mathrm{~mm}$ & 2.708 & 0.497 \\
\hline & Bronze $6 \mathrm{~mm}-13 \mathrm{~mm}$ Air & $\mathrm{Db} \mathrm{Br} 6 \mathrm{~mm}$ & 2.708 & 0.497 \\
\hline \multirow[t]{3}{*}{ Triple-pane window } & Clear $6 \mathrm{~mm}-13 \mathrm{~mm}$ Air & $\mathrm{Tr} \mathrm{Cl}$ Air & 1.778 & 0.684 \\
\hline & Clear $6 \mathrm{~mm}-13 \mathrm{~mm}$ Argon & Tr Cl Arg & 1.635 & 0.685 \\
\hline & Clear 6 mm - Low-E & Tr Low-E & 0.993 & 0.474 \\
\hline
\end{tabular}

\section{Results}

\subsection{Effect of window characteristics on total energy consumption}

The simulation can provide information on fuel breakdown or energy consumption by end-use as an output. It shows an annual summary of the energy consumption performance of the building. Table 5 shows the necessary information for further discussion in the example of the energy report for reference building parameters with single 3 mm clear glazing, $20 \% \mathrm{WWR}$, and a façade in the north direction.

Table 5. Energy consumption $(\mathrm{kWh})$ of the reference building

\begin{tabular}{cccccc}
\hline Room electricity & Lighting & Heating (Gas) & Cooling (Electricity) & DHW (Electricity) & Total annual energy consumption \\
\hline 1,170 & 3,587 & 29,260 & 3,725 & 6,476 & 44,218 \\
\hline
\end{tabular}

\subsubsection{Orientation}

As illustrated in Figure 2, the results of simulations with different building orientations show that the north and south façade of the building achieved the best energy performance. This result complies with the information from the literature review. As a result, the largest windows should be located on the south side of the building. Although the 
building with a north façade showed almost the same results as the building with a south façade, such values may be justified because the north side of the reference building has more window area than the south side.

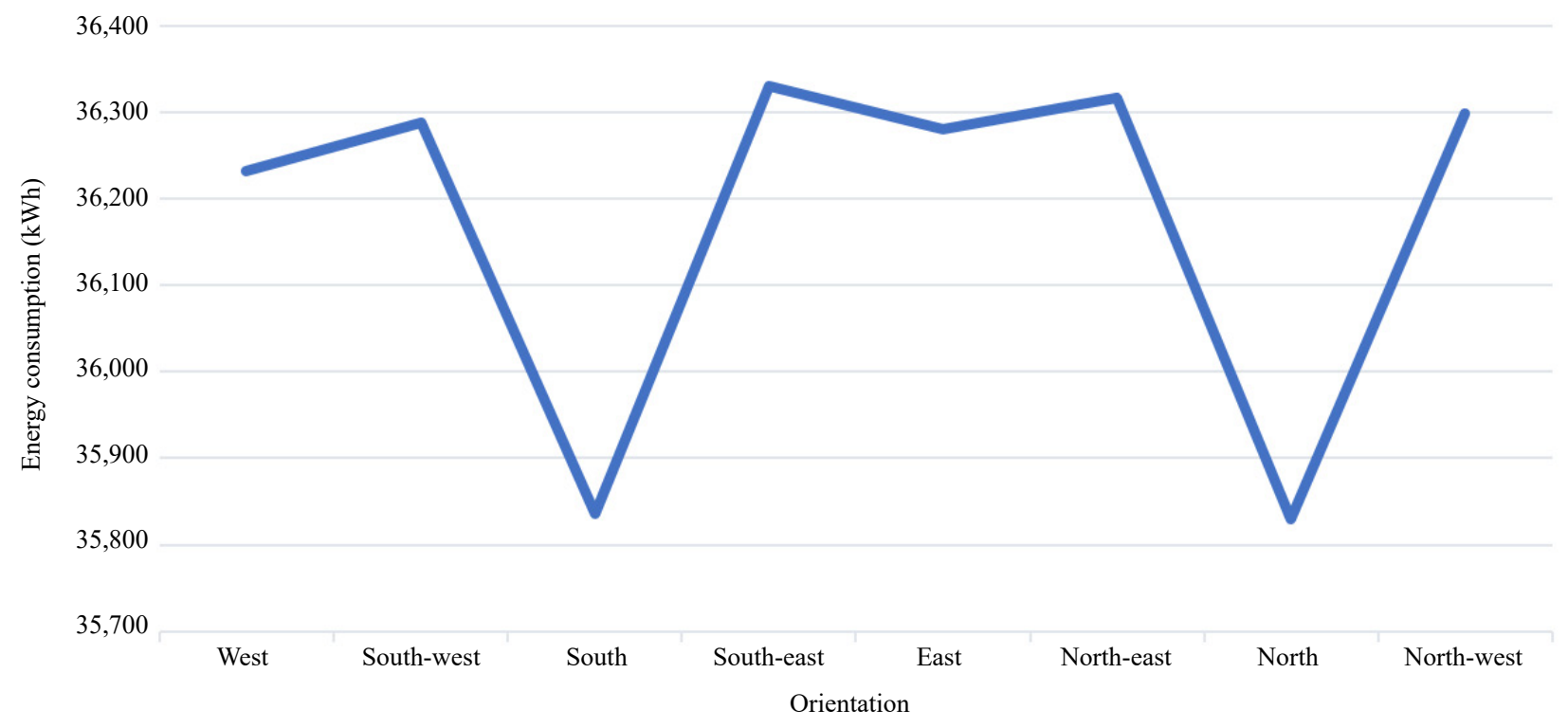

Figure 2. Effect of orientation on energy consumption $(\mathrm{kWh})$

\subsubsection{Window glazing}

Several simulations were also performed to determine the most effective window glazing (Figure 3). As shown in Figure 3, a triple-glazed window with a low-emissivity film has the most significant energy-saving potential. However, it should be noted that a double-pane window is much more efficient than a single-pane window, saving approximately $6,000 \mathrm{kWh}$ on average. Meanwhile, reducing energy consumption by 2,473 to $5,301 \mathrm{kWh}$ can be achieved using tripleglazed windows instead of double-glazed ones.

It should be pointed out that among the windows with the same U-value but different SHGCs, the ones with higher solar transmittance demonstrated better performance. In particular, clear double-pane windows reduced energy consumption by about $1,500 \mathrm{kWh}$ when compared to blue and bronze double-glazed windows. Using clear singleglazed windows instead of blue and bronze ones yields similar results, saving approximately 1,300 kWh. These results are consistent with the findings of Ihm et al. [23] and Kaasalainen et al. [27]. Hence, tinting affects the energy efficiency of the building, and clear glazing was found to be the most effective in the Nur-Sultan climate. Using lower SHGC windows may be efficient for facilities located in hot climate zones or only during the summer to reduce the energy for cooling.

The results show that some energy can be saved if the space between the panes is filled with argon instead of air. The difference is estimated to be insignificant. Additionally, changing the thickness of the single-glazed window from 3 $\mathrm{mm}$ to $6 \mathrm{~mm}$ had no significant effect on the amount of energy consumed. 


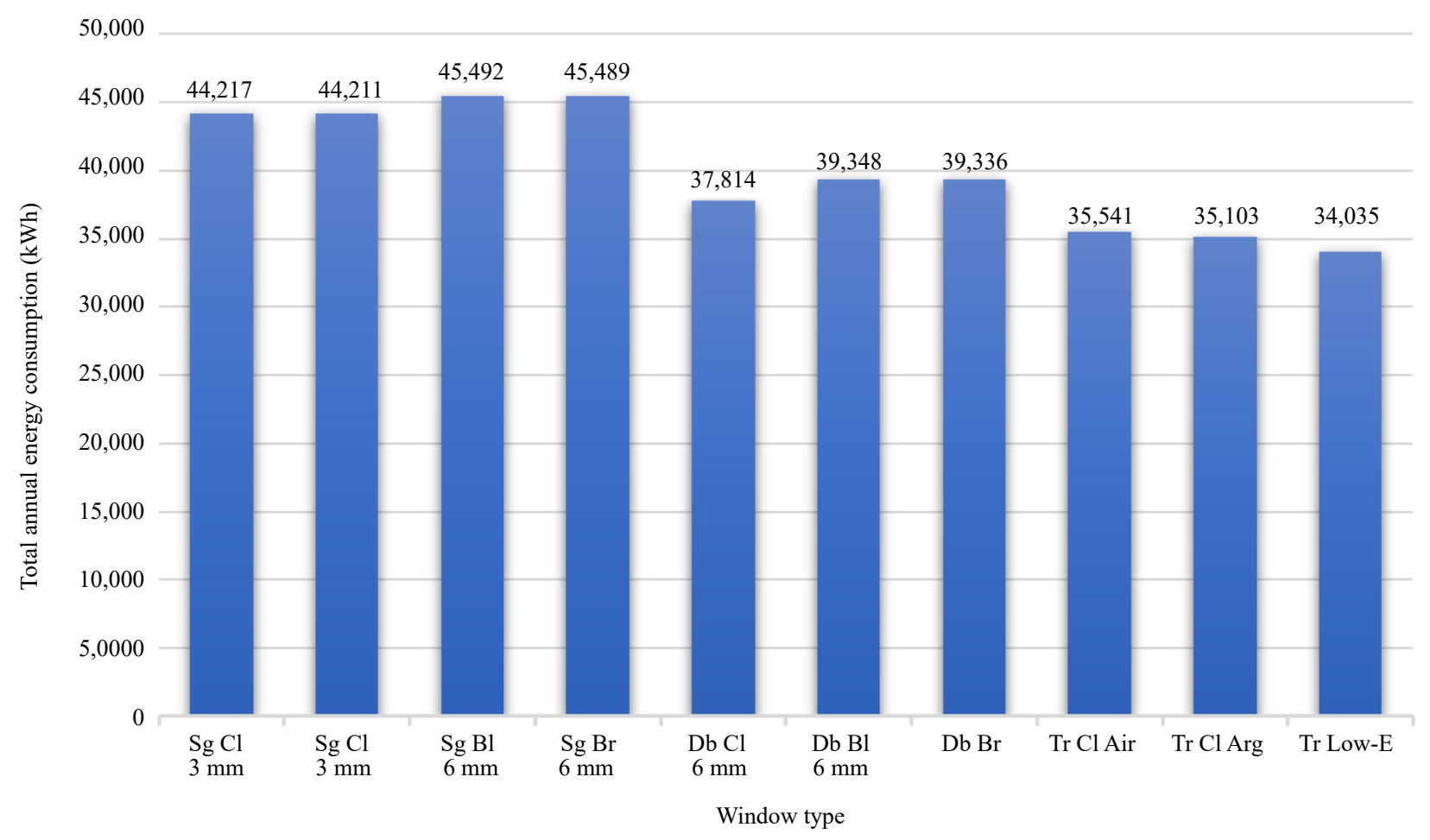

Figure 3. Effect of the type of glazing on energy consumption $(\mathrm{kWh})$

\subsubsection{Window-to-wall ratio (WWR)}

Another step in estimating the effect of window characteristics on energy consumption is simulations with different WWRs. The results (Figure 4) show that the energy savings potential increases as the WWR is reduced. Energy consumption remained almost unchanged as WWR increased from 0 to $12 \%$, while it increased linearly for WWR greater than $15 \%$.

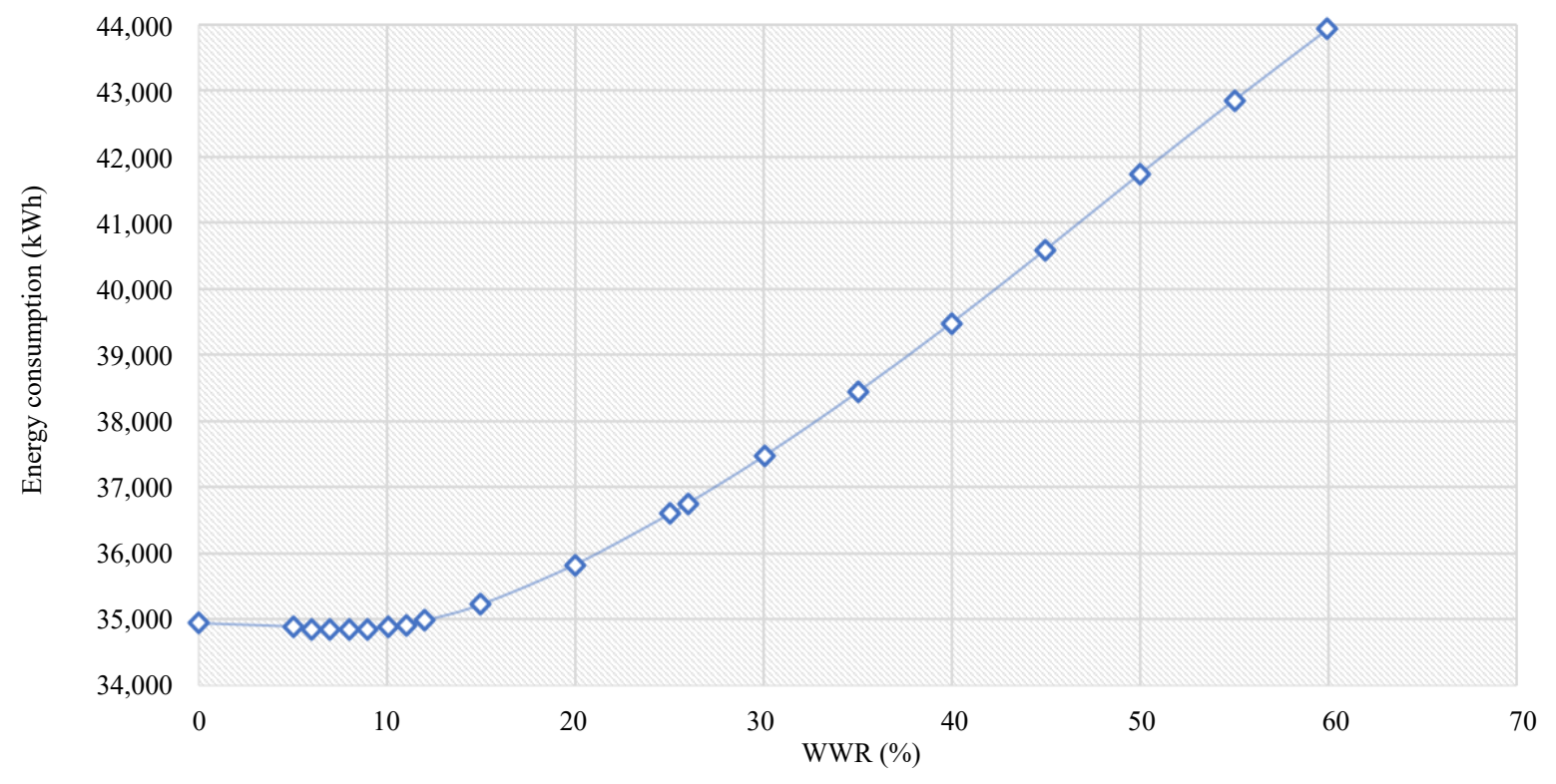

Figure 4. Effect of WWR on energy consumption (kWh) 
Notwithstanding the results obtained, the low value of WWR negatively affects the energy performance due to the additional load on general lighting. Passive houses reduce their electric energy consumption by using modern energysaving lamps for lighting systems and household appliances, as well as equipping them with automation tools that provide the most economical work cycle. Thus, another simulation with sensors and lighting control was performed, demonstrating the difference in general lighting consumption depending on the amount of daylight available. 150 lumen/ $\mathrm{m}^{2}$ of illuminance was explicitly established as a requirement to be met in the building. The following requirements also increased the power density for general lighting (Table 6).

Table 6. Lighting power requirements [35]

\begin{tabular}{cc}
\hline Type of space & Normalised lighting power density (W/M/100 lux) \\
\hline Bedrooms & 7.5 \\
Kitchen (domestic) & 5 \\
Lounges- small area & 7.5 \\
Toilets & 5 \\
\hline
\end{tabular}

Based on the proposed requirements, the characteristics of the building were adjusted, and the effect of WWR on energy for general lighting was estimated.

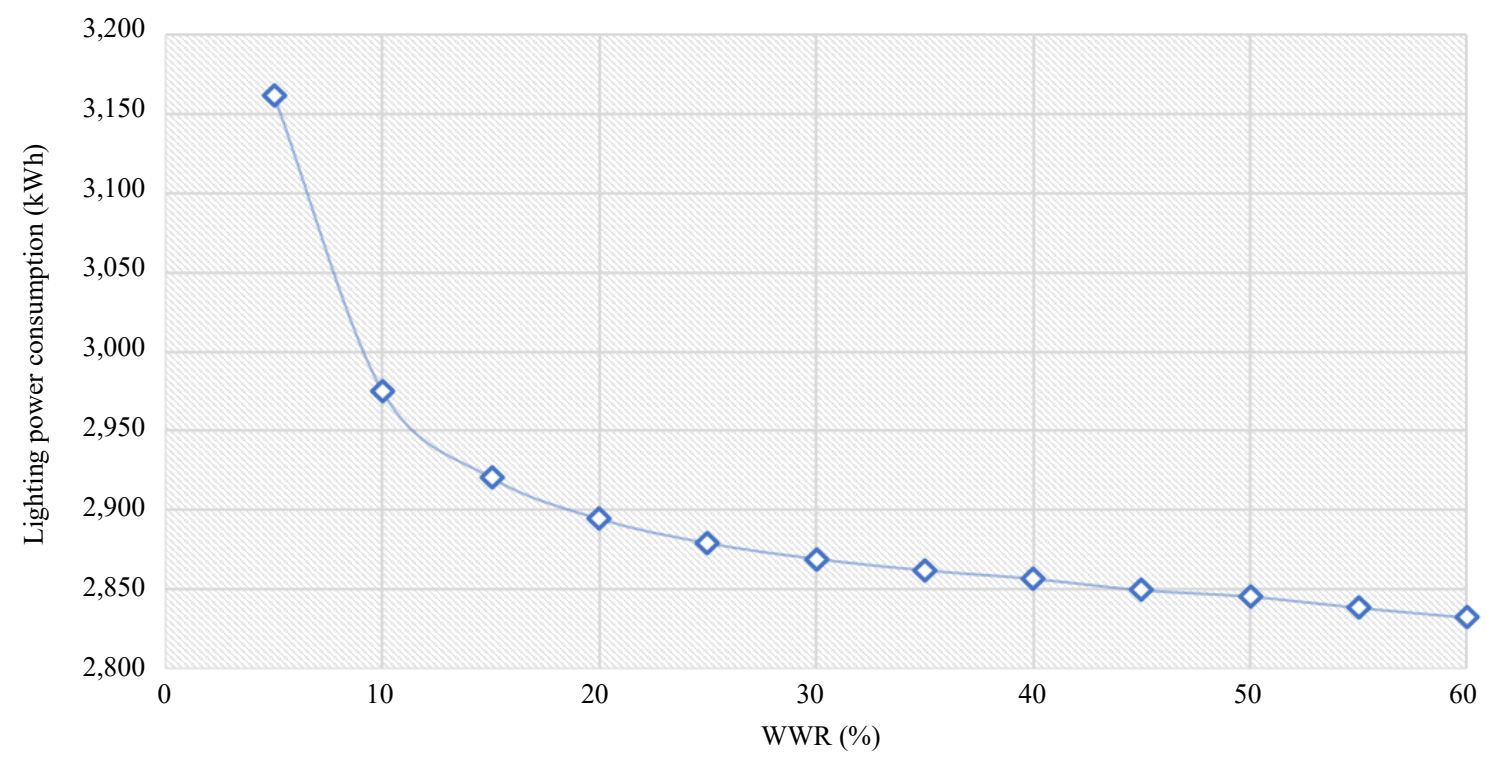

Figure 5. Effect of WWR on general lighting power consumption $(\mathrm{kWh})$

Figure 5 shows that the low value of WWR has a negative impact on energy consumption due to general lighting, despite savings on heating and cooling. The lighting electricity required for the building with $0 \%$ WWR is not included in the graph as it is two times greater than the energy needed for 5\% WWR. Therefore, it makes sense to keep the WWR in the range of 10 to $15 \%$.

\subsection{Effects of window characteristics on the comfort level}

Changing the window's characteristics affects not only energy consumption but also the comfort of the occupants. Specifically, thermal comfort could be affected. When the insulation properties of the windows are overly high, it can 
negatively affect the comfort level of the occupants due to rising temperatures and poor ventilation inside the building. However, all changes in window characteristics had no significant impact on the air and operating temperatures inside the rooms. Despite slight differences in all cases, the temperature remained within the acceptable range of 21.7 to 26.8 ${ }^{\circ} \mathrm{C}$. It can be justified by the presence of heating and cooling systems used to adjust the temperature in the building, which in turn creates additional loading and expenses.

A decrease in the WWR, on the other hand, can lead to a shortage of daylight. The comfort level was estimated based on two output types: the daylight factor and the illumination level. The general requirement for illuminance levels was 150 lumen $/ \mathrm{m}^{2}$. The optimal illuminance for general rooms was set in the range of 100 to 300 lux, with a drop of up to 25 lux in corridors and central areas. The daylight factor (DF) coefficient describes the difference between the amount of daylight available inside the rooms and outside the building. Therefore, rooms with an average DF of $2 \%$ or more can be considered daylit, but electric lighting may still be necessary to perform visual tasks. At the same time, rooms with an average DF of 5\% or more are considered strongly daylit, and electric lighting is unlikely to be used during the day [36].

a)

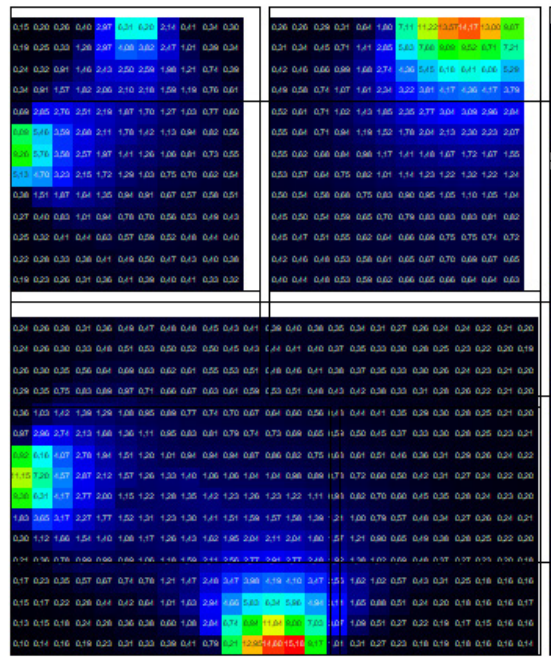

b)

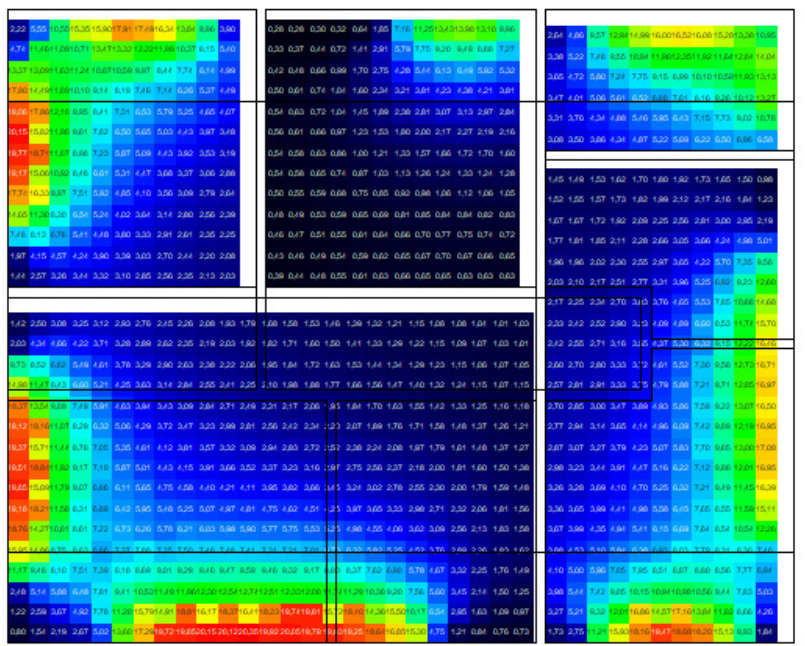

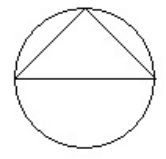

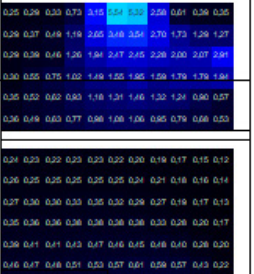

DF lux
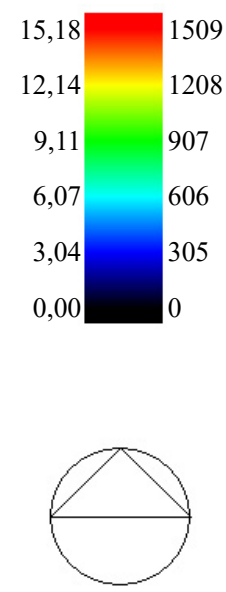

DF $\quad \operatorname{lux}$

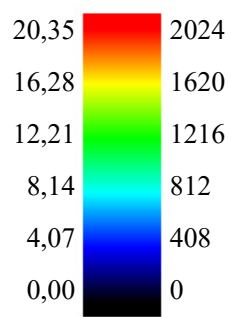

Figure 6. Daylight distribution examples for (a) $8 \%$ WWR and (b) $30 \%$ WWR 
Thus, based on the simulation of the distribution of daylight for different WWRs (as shown in Figure 6), it can be stated that a sufficient level of daylight can be achieved if the WWR exceeds $21 \%$.

\subsection{Discussion of results}

In general, optimising window properties to improve the energy performance of residential buildings can also influence the thermal and visual comfort of the occupants. In terms of energy efficiency, the WWR value appears to be limited by $12 \%$, which corresponds to the results obtained by Ihm et al. [23], with a 10\% WWR window showing the best performance in a cold climate. However, if the WWR increased by $10 \%$, annual energy consumption would increase from 35,000 to $36,590 \mathrm{kWh}$, and significant changes would occur in electricity use. Subsequently, WWR values between 15 to $20 \%$ may be suggested as an adequate compromise to achieve a satisfactory comfort level and energy performance.

One of the basic principles of comfort and energy savings in a passive home is ventilation. A sufficient volume of fresh air must enter the building to meet the passive house standard. This arrangement allows for the space to maintain an optimal level of comfort and humidity. An efficient exhaust ventilation system with recuperation is used in passive houses to meet these requirements. Building ventilation can cause large heat losses and significant energy costs. Therefore, instead of natural ventilation, it is proposed to use a recovery system. It is possible to reduce the operating costs of electricity and, as a result, the cost of purchasing equipment by using this system. By using special material from the recuperation equipment, the supplied air is cool and dry in the summer, and heated and humidified during the winter due to exhaust air. The reduction in energy spent on building ventilation is achieved by reducing the amount of external air intake through the review of the planning solution, rearrangement of internal spaces with similar functions, and a sound air distribution system to reduce the need for additional quantities [37].

The next big problem to be resolved is the lack of natural daylight in the rooms. A specific programme that adjusts lighting power based on differences in natural light can be implemented to reduce the energy costs of lighting space [38].

Additionally, the use of light-coloured walls, ceilings, floors, and furniture can increase daylight accumulation and distribution inside rooms. The implementation of tubular skylights, which can be described as a pipe that transmits sunlight with minimal loss, can significantly increase natural daylight while saving up to $50 \%$ of energy [28].

\section{Conclusion}

There are different optimal window geometry characteristics for each facade of the building to improve energy performance. Simulations show that it is necessary to maximise the solar gain in the cold conditions of Nur-Sultan. Consequently, designers may consider allocating most window openings on the southern side, while introducing the least amount of window area to the west and east. In addition to this, the northern facade of the building should be designed with minimum translucent walling. Some simulations also showed that the use of shading for windows helps to slightly reduce the energy for cooling during the summer.

The triple-glazed Low-E window outperformed the other Low-E windows tested in terms of energy performance of the reference building. As Low-E windows are more expensive than double-pane windows, they may require a life-cycle cost analysis to be approved for use in Kazakhstan. For the same reason, Ihm et al. [23] recommended double-glazed windows over triple-glazed windows in their research for South Korea. Additionally, the difference in the environmental impact of both types of windows could also be evaluated.

Finally, it was found that WWR in the range of 10 to $15 \%$ is the most optimal for the climate of Nur-Sultan. However, this value can be adjusted depending on the preference for a certain level of comfort.

The environment's sustainability lies in the fact that human needs must be met to the maximum degree in the building, which is supposed to have a minimal impact on the environment and non-renewable resource consumption throughout the life cycle. Around $40 \%$ of the energy generated in Kazakhstan is delivered to heat residential buildings. As previously mentioned, housing accounts for $24 \%$ of national heating demand. Subsequently, it is clear that an enormous amount of energy is lost during supply chain tranfers, and an excessive volume of fuel is merely wasted. 
This might be a topic of discussion for future research. In addition, energy savings positively influence the environment by reducing pollution from waste and emissions. Therefore, the implementation of passive houses, which contribute significantly to sustainability and energy efficiency, could be brought into further studies.

The results of this study could be used to improve the energy efficiency of buildings in Karagandy, which is the fourth largest city in Kazakhstan. It has a similar climate to Nur-Sultan. It is also located in the Dfb climate region according to the Koppen climate classification, along with the southern part of Canada, south-western Russia, Ukraine, Belarus, Baltic countries, southern coastal regions of Sweden and Finland. Thus, research outputs regarding the countries mentioned above could be thoroughly evaluated as guidance for subsequent research.

During the years 1936 to 2005, the climate in Kazakhstan has become significantly warmer. Every decade, the average annual temperature increased by $0.310^{\circ} \mathrm{C}$. Many regions became susceptible to abnormal heat, which increased by a factor of two, while the duration of abnormally low air temperatures decreased. Therefore, researchers can consider future climate changes when addressing the energy efficiency of buildings in Kazakhstan.

\section{Conflict of interest}

We have no conflict of interest to disclose.

\section{References}

[1] Safdar N, Chaudhry IS, Chaudhry MO. Energy Consumption, Environmental degradation and economic growth in developing countries. Pakistan Journal of Social Sciences. 2019; 39(2). Available from: https://media.teckiz.com/ pakistan-journal-of-social-sciences/pjss-bzu/2020/05/29/5ed125c340448.pdf [Accessed 1st June 2021].

[2] Nejat P, Jomehzadeh F, Taheri MM, Gohari M, Majid MZA. A global review of energy consumption, CO2 emissions and policy in the residential sector (with an overview of the top ten $\mathrm{CO} 2$ emitting countries). Renewable and Sustainable Energy Reviews. 2015; 43: 843-862. Available from: doi: 10.1016/j.rser.2014.11.066.

[3] Tushar Q, Bhuiyan M, Sandanayake M, Zhang G. Optimising the energy consumption in a residential building at different climate zones: Towards sustainable decision making. Journal of Cleaner Production. 2019; 233: 634-649. Available from: doi: 10.1016/j.jclepro.2019.06.093.

[4] Organisation for Economic Co-Operation and Development (OECD). Promoting energy efficiency in the residential sector in Kazakhstan: designing a public investment programme. OECD; 2012. Available from: https://www.oecd. org/env/outreach/KAZ\%20report_programme\%20design_ENG_web\%20version.pdf [Accessed 1st June 2021].

[5] Ministry of Industry and New Technologies of the Republic of Kazakhstan. On approval of the Program "Energy Saving - 2020". Government of the Republic of Kazakhstan. 2016. Available from: https://adilet.zan.kz/rus/docs/ P1300000904 [Accessed 1st June 2021].

[6] Badescu V, Rotar N, and Udrea I, Considerations concerning the feasibility of the German Passivhaus concept in Southern Hemisphere. Energy Efficiency. 2015; 8(5): 919-949. Available from: doi:10.1007/s12053-015-9332-8.

[7] Fu X, Qian X, Wang L, Energy efficiency for airtightness and exterior wall insulation of passive houses in hot summer and cold winter zone of China. Sustainability. 2017; 9(7): 1097. Available from: doi: 10.3390/su9071097.

[8] Tokbolat S, Karaca F, Durdyev S, Nazipov F, Aidyngaliyev I. Assessment of green practices in residential buildings: A survey-based empirical study of residents in Kazakhstan. Sustainability. 2018; 10(12): 4383. Available from: doi: 10.3390/su10124383.

[9] Akhanova G, Nadeem A, Kim JR, Azhar S. A framework of building sustainability assessment system for the commercial buildings in Kazakhstan. Sustainability. 2019; 11(17): 4754. Available from: doi: 10.3390/su11174754.

[10] Aldawi F, Date A, Alam F, Khan I, Alghamdi M. Energy efficient residential house wall system. Applied Thermal Engineering. 2013; 58(1-2): 400-410. Available from: doi: 10.1016/j.applthermaleng.2013.02.023.

[11] Tahmasebi MM, Banihashemi S, Hassanabadi MS. Assessment of the variation impacts of window on energy consumption and carbon footprint. Procedia Engineering. 2011; 21: 820-828. Available from: doi: 10.1016/ j.proeng.2011.11.2083.

[12] Saffari M, De Gracia A, Fernández C, Cabeza LF. Simulation-based optimisation of PCM melting temperature to improve the energy performance in buildings. Applied Energy. 2017; 202: 420-434. Available from: doi: 10.1016/ 
j.apenergy.2017.05.107.

[13] Cheung CK, Fuller RJ, Luther MB. Energy-efficient envelope design for high-rise apartments. Energy and Buildings. 2005; 37(1): 37-48. Available from: doi: 10.1016/j.enbuild.2004.05.002.

[14] Kerimray A, Bektineyev R, Rojas-Solórzano L. Energy efficiency options for buildings: insights from buildings energy audit reports in Kazakhstan. In: 4th IET Clean Energy and Technology Conference (CEAT 2016), 14-15 November 2016, Kuala Lumpur, Malaysia. Kuala Lumpur: IET Conference Proceedings; 2016. Available from: doi: 10.1049/cp.2016.1280.

[15] Agency for Strategic Planning and Reforms of the Republic of Kazakhstan. Women and Men of Kazakhstan 2012-2016. Government of the Republic of Kazakhstan. 2017. Available from: https://gender.stat.gov.kz/file/ WomenAndMan.pdf [Accessed 1st June 2021].

[16] Agency for Strategic Planning and Reforms of the Republic of Kazakhstan. Statistics of Nur-Sultan City. Government of the Republic of Kazakhstan. 2021. Available from: https://stat.gov.kz/region/268012?lang=ru [Accessed 1st June 2021].

[17] Sadineni SB, Madala S, Boehm RF. Passive building energy savings: A review of building envelope components. Renewable and Sustainable Energy Reviews. 2011; 15(8): 3617-3631. Available from: doi: 10.1016/ j.rser.2011.07.014.

[18] Obrecht TP, Premrov M, Leskovar VŽ. Influence of the orientation on the optimal glazing size for passive houses in different European climates (for non-cardinal directions). Solar Energy. 2019; 189: 15-25. Available from: doi: 10.1016/j.solener.2019.07.037.

[19] Alibaba H. Determination of optimum window to external wall ratio for offices in a hot and humid climate. Sustainability. 2016; 8(2): 187. Available from: doi: 10.3390/su8020187.

[20] Feng G, Chi D, Xu X, Dou B, Sun Y, Fu Y. Study on the influence of window-wall ratio on the energy consumption of nearly zero energy buildings. Procedia Engineering. 2017; 205: 730-737. Available from: doi: 10.1016/ j.proeng.2017.10.003.

[21] Yang Q, Liu M, Shu C, Mmereki D, Hossain U, Zhan X. Impact analysis of window-wall ratio on heating and cooling energy consumption of residential buildings in hot summer and cold winter zone in China. Journal of Engineering. 2015; 2015. Available from: doi: 10.1155/2015/538254.

[22] Liu H, Zhang Z, Ma X, Lu W, Li D, Kojima S. Optimization analysis of the residential window-to-wall ratio based on numerical calculation of energy consumption in the hot-summer and cold-winter zone of China. Sustainability. 2021; 13(11): 6138. Available from: doi: 10.3390/su13116138.

[23] Ihm P, Park L, Krarti M, Seo D. Impact of window selection on the energy performance of residential buildings in South Korea. Energy Policy. 2012; 44: 1-9. Available from: doi: 10.1016/j.enpol.2011.08.046.

[24] Košir M, Iglič N, Kunič R. Optimisation of heating, cooling and lighting energy performance of modular buildings in respect to location's climatic specifics. Renewable Energy. 2018; 129: 527-539. Available from: doi: 10.1016/ j.renene.2018.06.026.

[25] Susorova I, Tabibzadeh M, Rahman A, Clack HL, Elnimeiri M. The effect of geometry factors on fenestration energy performance and energy savings in office buildings. Energy and Buildings. 2013; 57: 6-13. Available from: doi: 10.1016/j.enbuild.2012.10.035.

[26] Su X, Zhang X. Environmental performance optimisation of window-wall ratio for different window type in hot summer and cold winter zone in China based on life cycle assessment. Energy and Buildings. 2010; 42(2): 198202. Available from: doi: 10.1016/j.enbuild.2009.08.015.

[27] Kaasalainen T, Mäkinen A, Lehtinen T, Moisio M, Vinha J. Architectural window design and energy efficiency: Impacts on heating, cooling and lighting needs in Finnish climates. Journal of Building Engineering. 2020; 27 : 100996. Available from: doi: 10.1016/j.jobe.2019.100996.

[28] Omer AM. Renewable building energy systems and passive human comfort solutions. Renewable and Sustainable Energy Reviews. 2008; 12(6): 1562-1587. Available from: doi: 10.1016/j.rser.2006.07.010.

[29] Harmati N, Magyar Z. Influence of WWR, WG and glazing properties on the annual heating and cooling energy demand in buildings. Energy Procedia. 2015; 78: 2458-2463. Available from: doi: 10.1016/j.egypro.2015.11.229.

[30] Ochoa CE, Aries MB, van Loenen EJ, Hensen JL. Considerations on design optimisation criteria for windows providing low energy consumption and high visual comfort. Applied Energy. 2012; 95: 238-245. Available from: doi: 10.1016/j.apenergy.2012.02.042.

[31] Crawley DB, Lawrie LK, Winkelmann FC, Pedersen CO. EnergyPlus: New capabilities in a whole-building energy simulation program. In: Seventh International IBPSA Conference 2001, 13-15 August 2001, Rio de Janeiro, Brazil. Brazil: Proceedings of Building Simulation; 2001. p. 51-58. 
[32] Crawley DB, Hand JW, Kummert M, Griffith BT. Contrasting the capabilities of building energy performance simulation programs. Building and Environment. 2008; 43(4): 661-673. Available from: doi: 10.1016/ j.buildenv.2006.10.027.

[33] Pawar BS, Kanade G. Energy Optimization of Building Using Design Builder Software. International Journal of New Technology and Research. 2018; 4(1): 69-73. Available from: https://media.neliti.com/media/ publications/263152-energy-optimization-of-building-using-de-a8e3c6e9.pdf [Accessed 1st June 2021].

[34] González JP, Yousif C. Prioritising energy efficiency measures to achieve a zero net-energy hotel on the island of Gozo in the central Mediterranean. Energy Procedia. 2015; 83: 50-59. Available from: doi: 10.1016/ j.egypro.2015.12.195.

[35] European Commission. EU GPP Criteria for Indoor Lighting. 2013. Available from: https://studylib.net/ doc/18231255/eu-gpp-criteria-for-indoor-lighting [Accessed 1st June 2021].

[36] Roche L, Dewey E, Littlefair P. Occupant reactions to daylight in offices. International Journal of Lighting Research and Technology. 2000; 32(3): 119-126. Available from: doi: 10.1177/096032710003200303.

[37] Xing Y, Hewitt N, Griffiths P. Zero carbon buildings refurbishment-A Hierarchical pathway. Renewable and Sustainable Energy Reviews. 2011; 15(6): 3229-3236. Available from: doi: 10.1016/j.rser.2011.04.020.

[38] Dubois M-C, Blomsterberg Å. Energy saving potential and strategies for electric lighting in future North European, low energy office buildings: A literature review. Energy and Buildings. 2011; 43(10): 2572-2582. Available from: doi: 10.1016/j.enbuild.2011.07.001. 